\title{
Relating Perceptual Learning Styles of Engineering Students with Scanning Information in Text Scores
}

\author{
Asmara Shafqat ${ }^{1} \&$ Najeeb us Saqlain ${ }^{2}$ \\ ${ }^{1}$ Department of Humanities, Ned University of Engineering \& Technology, Karachi, Pakistan \\ ${ }^{2}$ Department of English, College of Science \& Humanities in Rumah, Majmaah University, Saudi Arabia \\ Correspondence: Asmara Shafqat, Department of Humanities, Ned University of Engineering \& Technology, \\ Karachi, Pakistan. E-mail: asmara.tayyeb@yahoo.com
}

Received: May 27, 2019 Accepted: June 20, 2019 Online Published: August 26, 2019

doi:10.5539/ijel.v9n5p257 URL: https://doi.org/10.5539/ijel.v9n5p257

\begin{abstract}
There are numerous factors, which reasonably affect teachers' instructions. One of these factors is being aware of the learners' learning styles. Shea's work (1983) contributed that there is a strong correlation between learning styles and reading comprehensions. The present study investigated the correlation between Perceptual learning styles and scanning information in text scores. To achieve this, researcher randomly selected 382 undergraduates (male and female) engineering students of the Public sector Engineering University. Learning style survey questionnaire by Andrew D. Cohen, Rebecca L. Oxford, and Julie C. Chi (2001) was employed to examine the Perceptual learning style patterns and learning styles with respect to gender. In addition to this, reading test was conducted based on scanning skill. Pearson product-moment correlation test was applied to examine the correlation between the variables. It was found that a correlation exists between learning styles of engineering students and scanning information in the text. In addition to this, gender does play role in learning style preferences. This result would create awareness among all instructors or teachers the importance of learners' unique learning style preferences that consequently affect teaching methodologies in all educational settings.
\end{abstract}

Keywords: learning styles, perceptual learning styles, scanning skill, reading comprehension

\section{Introduction}

Reading competency in English is the core skill for engineering students. Through reading, they can grasp professional information and knowledge not only in academic settings, but also in the future career. No other language is extensively spread and used around the world as English and this includes Pakistan as well. Universities can play a leading role in polishing the future engineers to handle the increasing demand of attaining reading skills in the English language. According to Spretnak (1987), engineers spend nearly twenty-three percent of their total time in reading technical and business material.

Searching skill is another reading skill which is progressively important and implicates different processes than to reading to learn the whole passage. According to Dreher (1992), the aim of searching task is to locate or scan the specific information. In this process, students are not involved in reading the whole passage or reading material, instead, they ignore the irrelevant material. Not only engineers but also adults also have been observed to spend most of the time in scanning information for different purposes (Guthrie, Seifert, \& Kirsch, 1986; Mikulecky, 1982; Kirsch \& Guthrie, 1984). Furthermore, Brown (2007) elaborated that scanning skill is crucial in reading any piece of information as it facilitates extracting required information without wasting any time. Anderson et al. (1995) explained the use of scanning skill and stated that scanning skill is used to evaluate the reading material through quickly moving eyes and adapting speedy reading to comprehend the whole structure.

Successful reading programs in Pakistani educational system have been one of the critical issues. All English language teachers and practitioners facing huge challenges along with the learners. Various methods, approaches and techniques have been explored and discovered by the experts recently that deliver the need of modification in the curriculum, syllabus and instructional planning for the English language learners that can be matched with their preferred learning styles (Scanlon, Deshler, \& Schumaker, 1996). This requirement is particularly important and inevitable at undergraduate level, specifically in engineering context where the students' need to read for technical or specific information in English. 
Research has recognized that some people prefer a singular (e.g., visual) style of learning and some incline to prefer diverse manners of learning (e.g., Visual plus auditory) (Fleming, 1995; Sarasin, 1998). Understanding or apprehending learning styles could be taken as a crucial factor of handling teaching strategies (Jaeger, Freeman, $\&$ Whalen, 2007).

The selected area of this study is of extraordinary significance in all learning settings, especially, in Pakistani educational context because it has been ignored up till now. No considerable attention has been given to the identification of learners' learning styles' applications and practices in the classrooms. This study highlighted the identification of Perceptual learning styles as it is highly related to reading skill.

This research investigated The Perceptual learning style preferences of undergraduate engineering students with respect to gender, and the correlation between Perceptual learning styles and the scanning information in text scores.

\section{Literature Review}

Defining learning style has been a difficult concern for the scholars in this field. The definition of learning style, according to Reid (1987) is "a term that describes the variations among learners in using one or more sense to understand, organize, and retain experience" (p. 89). For Claxton and Ralston (1978) it is a "consistent way of responding and using stimuli in the context of learning" (p. 7). Felder and Henriques (1995) gave a similar version to some extent as he said: "learning style describes the ways in which an individual characteristically acquire, retains and retrieves information" (p. 21). Grasha (1996) highlighted learning styles as representing the various roles learners perform in their classrooms, social synergy, interaction and communication among students, course contents and teachers. Smith and Renzulli (1984) indicated these definitions in a range of terms: "preferred sensory modalities (e.g., Visual, auditory, tactile) to descriptions of personality characteristics that have implications for behaviour patterns in learning situations (e.g., the need for structure versus flexibility)" (p. 45)

Mostly, learning styles might be reflected into three broad categories.

i) Perceptual Modality

ii) Information processing modality

iii) Personality and social interaction

According to Oxford (2003) learning styles "are the general approaches: global or analytic, auditory or visual - that students use in acquiring a new language or in learning any other subject."

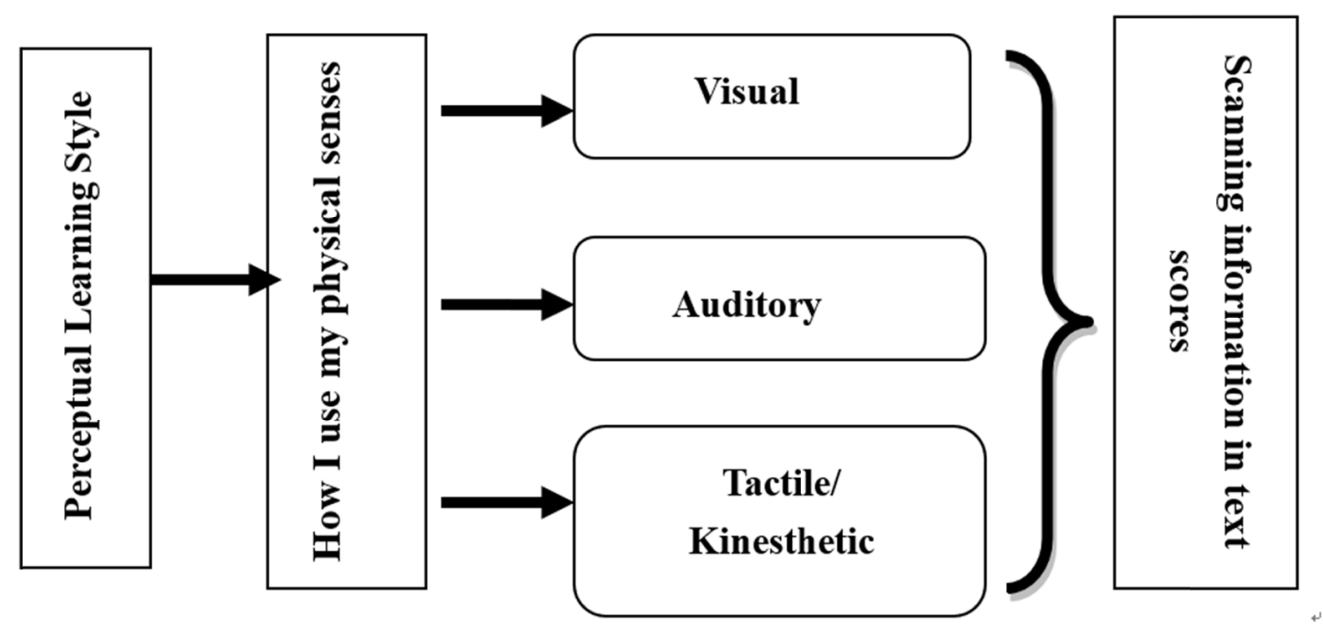

Figure 1. Conceptual frame work for the study

Visual, auditory and tactile are the main dimensions of Perceptual learning styles have been focused in this study.

\subsection{Evaluation of Former Studies on the Correlation Between Gender and Learning Styles}

This is the domain of which past studies have incredibly contributed and expanded our understanding. It 
improved our insight into the importance of investigating and distinguishing learners, learning style with respect to gender difference (Akhlaghi, Mirkazemi, Jafarzade, \& Akhlaghi, 2018). The aim of this kind of studies was to present prominent variations in learning styles with respect to gender. However, there are some studies which reported that gender did not influence significantly on the learner's learning style. Some researchers have shown that male and female learners adopted same learning styles (Sarabi-Asiabar et al., 2015).

\subsection{Learning Styles and Reading}

Carbo (1984) delivered a different perspective of learning styles which was based on reading styles. It was a favourable method for reading features, as a learning choice and to label them "reading style" in overall form, which shared to the theory to a great extent; particularly, the studies that were conducted on the correlation between learning preferences and in collaboration with learning style. Linguists gave unique instances as they recognize reading that was based on learning preferences (Carbo, Dunn, \& Dunn, 1986).

When analysing sensory reading comprehension and learning styles, it was revealed that there was an association between auditory, kinesthetic, and reading comprehension levels and visual learning styles (Williams, 2010).

Geoghegan (1996) adopted a test that presented four sensory learning styles: visual, auditory, tactile and kinesthetic, results established that the kinesthetic and tactile, have collectively been more than the collective visual and auditory, so she summarized that the group was kinesthetically motivated.

\subsection{The Relationship Between Learning Style and Reading Achievement}

Carbo (1983a) reported that comparative research dealing with good and poor readers reveals considerable dissimilarity between the two groups on various elements of learning style, "particularly, perception, motivation, persistence, responsibility, structure, design, time of day and hemispheric preference" (p. 490). She further concluded that there are learners who do not learn through step-by-step guided teaching. Carbo's findings supported to those of Price, Dunn and Sanders (1981), who used the LSI. Their research revealed that the elements assessing persistence, responsibility, ability to function fine in the afternoon and preference for an unceremonious strategy best distinguished between third and sixth class students who were identified as having extraordinary and stumpy reading success. The better readers preferred learning in a softly ignited, proper setting, required mobility, and were energetic, determined and accountable. They did not consider learning through their kinesthetic and tactile modalities did not function greatest in the afternoon or require food intake.

Price, Dunn and Sanders' (1981) findings proposed that specific learning styles are the predictors to foresee any change in the student achievement, whether they would be good readers or not, for instance, the persistent, self-motivated, and responsible who do not choose to learn in a tactile learning style or kinesthetically. Students' self-concepts are highly correlated to desirable learning habits (Griggs \& Price, 1981).

However, regardless of the student's identified perceptual strength, a treatment involving a visual approach achieved significance at the .05 level with students possessing auditory, visual and auditory/visual perceptual strengths. (Price, Dunn, \& Sanders, 1981)

Summary of the research findings comparing learning styles and reading achievement reveals several consistent patterns. Students can accurately identify their preferred learning styles. When students are taught through preferred styles, academic performance is significantly better and conversely, when a mismatch occurs, achievement is significantly poorer.

\subsection{Pakistani Context of Learning Styles}

In Pakistan, identification of learning styles has not been given due importance in teaching and learning. Hardly any research done in learning style in relationship with reading, reading ability or reading comprehension. Khurshid and Mahmood (2012) found that social science students enjoy and mostly get involved in group type of learning style they prefer discussions, contrary to general science students love to employ auditory, kinesthetic and tactile learning style. Farooq and Regnier (2011) elaborated, in Pakistan, instructors may affect the quality of education in a very negative way due to the fact that they are mostly untrained which consequently eliminates the awareness of learning styles.

There are other studies conducted on learning styles in Pakistan in relation with academic for example Akhtar, and Arif (2011) examined the relationship of cognitive styles with students 'academic achievement in the subject of science at the elementary level'. A cross-sectional study; Shukr, Zainab, and Rana (2013) identified and investigated the learning styles of undergraduate and postgraduate students of medical studies; perceptual learning styles were examined with respect to academic achievement and gender by Siddique, Abbas, Riaz, and Nazir (2014); Farooq and Regnier (2011) tried to explore that how the quality of learning was influenced by 
learning styles at different levels; Khurshid and Mahmood (2012) explained the learning styles of natural sciences; Gujjar and Tabassum (2011) assessed learning styles not only of students but also of teachers at federal college of education humanities students at graduate level.

Same is the case with reading comprehension and reading ability. In this case as well not a very significant work has been done in Pakistan in relation to learning styles. Shaheen (2015) conducted a study on the relationship Between practices and beliefs of English teaching reading instruction. Rahim (2003) investigated how to facilitate teaching in developing reading comprehension skill. Hashwani (2000) studied different variables that affect reading difficulties in children like pronunciation, phonics, spellings and others but not included the learning styles of the students.

These all studies discovered that a little research was done in the area of learning style in relationship with reading and reading comprehension in Pakistan; therefore, this research gap provides a rationale for the present study. The present study will be great contribution in the field of literature of learning style in Pakistani context. It will facilitate other research scholars to discover various contexts of learning styles, especially for engineering students in a relationship with important reading skill, scanning.

\subsection{Scanning for Specific Information}

Scanning is reading for particular facts of information. It is a purposeful reading, and its purpose is to acquire very specific reading goals. Jordon (1980) has said a variety of texts appropriate for scanning are dictionaries, indexes, maps, advertisements, materials and reference etc.

According to Yussen, straight and Payne (1993), scanning is the most common activity used in schools, colleges or university where students need to locate or search required information to answer a query, look up for an unknown fact, and definition of unfamiliar terms or concepts asked by the teacher. Guthrie (1988); Kirsch and Mosenthal (1990) pointed out that a lot of research has been done in examining the processes involved in reading the texts to recall or remember and comprehend them, but little research has been conducted in examining the processes involved in searching or locating information in texts.

According to Kirsch and Jungeblut (1986), the U.S. National Assessment of Educational Progress (NAEP) highlighted three different facets of reading comprehension (i) locating or scanning information in text, (ii) interpreting and producing text information and (iii) organising principle and generating a theme from the text information.

The difference between proficiency in reading comprehension and in scanning the required information in the text is related to the view of unique processing (Bransford, Franks, Morris, \& Stein, 1979). On the basis of this model, the achievement of competence in reading comprehension Is not possible to assist achievement in locating information, because the processing demand for the two kinds of tasks is not the same.

The primary objectives of the Study are to:

- To provide research in Pakistani context regarding Perceptual learning styles and scanning information in text.

- To investigate the Perceptual Learning styles of engineering students.

- To investigate the Perceptual learning styles with respect to gender.

- To investigate the correlation between Perceptual learning styles and scanning information in text scores.

\section{Method}

The researcher used correlational design. Creswell (2002) stated that correlational design is useful to examine the association or relationship between variable $\mathrm{X}$ and variable $\mathrm{Y}$. Correlational designs are the method in quantitative studies in which the researchers investigate the level of relation or association between two variables or more using method of correlational analysis or statistical method. This kind of relationship is termed as a number predicting if the variables are associated or not or if one variable can predict or influence another.

The present study attempted to examine the correlation or relationship between the two variables: learning styles and scanning information in text scores.

\subsection{Research Questions}

1) What are the perceptual learning styles preferences of engineering students at undergraduate level in terms of the dimensions?

2) What are the perceptual learning styles preferences of engineering students at undergraduate level with respect 
to gender?

3) Is there any correlation between perceptual learning styles of engineering students and scanning information in text scores?

\subsection{Hypotheses}

1) $\mathrm{H}_{01}$ : There is no statistically significant correlation between visual learning style and scanning information in text score.

2) $\mathrm{H}_{02}$ : There is no statistically significant correlation between auditory learning style and scanning information in text score.

3) $\mathrm{H}_{03}$ : There is no statistically significant correlation between kinesthetic learning style and scanning information in text score.

\subsection{Population}

The population of this study is undergraduate engineering students at Public Sector University. In this study, probability sampling approach with simple random technique was used from which 382 students were selected. The target population was undergraduate engineering students of Pakistan.

\subsection{Research Instruments}

- Learning Style Survey questionnaire created by Cohen, Rebecca Oxford and Julie Chi (2003) was adopted and in this study only Perceptual learning style section was investigated.

- Scanning information test was adapted from Reading for IELTS by Els Van Geyte (2011), 1st edition.

\section{Result}

Table 1. Over all perceptual learning style preferences of engineering students

\begin{tabular}{llll}
\hline & & $\mathrm{f}$ & $\%$ \\
\hline How do students use physical senses & Visual & 111 & 29.1 \\
& Auditory & 128 & 33.5 \\
& Kinesthetic & 143 & 37.4 \\
\hline
\end{tabular}

In the selected random sample of 382 participants, the Table 1 shows that in the First part: How do students use my physical senses, Kinesthetic is the most preferred learning style with the frequency of $143(37.4 \%)$.

Table 2. Perceptual learning style preferences with respect to gender

\begin{tabular}{|c|c|c|c|c|c|}
\hline & & \multicolumn{4}{|c|}{ Gender } \\
\hline & & \multicolumn{2}{|c|}{ Male } & \multicolumn{2}{|c|}{ Female } \\
\hline & & $\mathrm{f}$ & $\%$ & $\mathrm{f}$ & $\%$ \\
\hline \multirow[t]{3}{*}{ How do students use physical senses } & Visual & 47 & 42.3 & 64 & 57.7 \\
\hline & Auditory & 72 & 56.2 & 56 & 43.8 \\
\hline & Kinesthetic & 58 & 40.6 & 85 & 59.4 \\
\hline
\end{tabular}

When investigated learning style through the gender perspective Table 2, in some learning styles a difference in the preferences has been observed. Table 2 demonstrates in the first part, first group Visual learning style, females have dominated (male $=42.3 \%$ vs. female $=57.7 \%$ ). In Auditory learning style, males ruled over female $($ male $=56.2 \%$ vs. female $=43.8 \%)$. While Kinesthetic used more by female (male $=40.6 \%$ vs. female $=$ $59.4 \%)$. 


\subsection{Hypotheses Testing}

Table 3. Pearson's product moment correlations for visual with scanning information in text score

\begin{tabular}{llll}
\hline & & Visual & Scanning Information In Text Score(V) \\
\hline Visual & Pearson Correlation & 1 & $.979^{* *}$ \\
& Sig. (2-tailed) & & .000 \\
& $\mathrm{n}$ & 111 & 111 \\
Scanning Information In Text Score(V) & Pearson Correlation & $.979^{* *}$ & 1 \\
& Sig. (2-tailed) & .000 & \\
& $\mathrm{n}$ & 111 & 111 \\
\hline
\end{tabular}

Note. ${ }^{* *} \mathrm{p}<.01$.

A Pearson product-moment correlation coefficient was measured to calculate the relationship or association between the Visual learning style and Scanning information in text score (V). As expected, Table 3 showed a very strong positive correlation between the two variables, $r=.979^{* *}, n=111, p=.000$. The significance value is $(p=0.000)$ less than the standard level of alpha $(p=.05)$. Therefore, it is concluded that alternative hypothesis was accepted and null hypothesis was rejected. It can be said that there is a statistically significant relationship between visual learning style and scanning information in text score $(\mathrm{V})$.

Table 4. Pearson's product moment correlations for auditory with scanning information in text score

\begin{tabular}{llll}
\hline & & Auditory & Scanning Information In Text Score(A) \\
\hline Auditory & Pearson Correlation & 1 & $.981^{* *}$ \\
& Sig. (2-tailed) & & .000 \\
& $\mathrm{n}$ & 128 & 128 \\
Scanning Information In Text Score(A) & Pearson Correlation & $.981^{* *}$ & 1 \\
& Sig. (2-tailed) & .000 & \\
& $\mathrm{n}$ & 128 & 128 \\
\hline
\end{tabular}

Note. ${ }^{* *} \mathrm{p}<.01$.

A Pearson product-moment correlation coefficient was investigated to examine the relationship between the Auditory learning style and Scanning information in text score (A). Table 4 revealed a very significant positive correlation between the two variables, $r=.981^{* *}, n=128, p=.000$. The significance value is $(p=.000)$, less than standard level of alpha $(p=0.05)$. It is concluded that alternative hypothesis was accepted and null hypothesis was rejected. It can be claimed that there was statistically a very significant relationship and association between auditory learning style and scanning information in text score (A).

Table 5. Pearson's product moment correlations for Tactile/Kinesthetic with scanning information in text score

\begin{tabular}{llll}
\hline & & $\begin{array}{l}\text { Tactile/ } \\
\text { Kinesthetic }\end{array}$ & Scanning Information In Text Score(K) \\
\hline Tactile/ & Pearson Correlation & 1 & $.986^{* *}$ \\
Kinesthetic & Sig. (2-tailed) & & .000 \\
& $\mathrm{n}$ & 143 & 143 \\
Scanning Information In Text Score(K) & Pearson Correlation & $.986^{* *}$ & 1 \\
& Sig. (2-tailed) & .000 & \\
& $\mathrm{n}$ & 143 & 143 \\
\hline
\end{tabular}

Note. ${ }^{* *} \mathrm{p}<.01$.

A Pearson product-moment correlation coefficient was applied, to measure the relationship between the Tactile/Kinesthetic learning style and Scanning information in text score $(\mathrm{K})$. Table 5 presented a strong positive correlation between the two variables, $r=0.986^{* *}, n=143, p=0.000$. The significance value is $(p=0.000)$, less than the standard level of alpha $(\mathrm{p}=.05)$. Therefore, it is concluded that alternative hypothesis was accepted and null hypothesis was rejected, which demonstrated that there was statistically significant relationship between Kinesthetic learning style and scanning information in text score $(\mathrm{K})$. 


\section{Conclusions}

The first aim of the present research was to explore the Perceptual Learning style preferences of engineering undergraduate students. Besides, the researcher explored the gender difference in these preferred learning style. In addition to this, the most important aim was to examine any possible correlation between learning style preferences and scanning information in text scores, with intent, highlighting the crucial significance of understanding learning styles not only for learners but also for teachers. Decisively, underlining the misunderstanding between reading comprehension and most important reading skill under discussion here was scanning skill.

In the first dimension, perceptual or sensory learning style which represented how students use physical senses, generally, it was assumed that students who were visually strong they could only read efficiently, but as the researcher explored engineering students learning styles so it was observed that predominantly kinesthetic learning style was used by undergraduate engineering students. Students understand better and take keen interest if a teacher and instructor make them involved in group activities, pair work, making assignments, giving presentations and allow them to move while doing any task in the classroom. The instructional plan should be such in which students tend to move for some time and not sitting still continuously. Kinesthetic students find it easier to learn practically which represented the quality of being engineering students. The teacher must offer hands-on practices to comprehend language, culture or any other subject by using nonverbal strategies as well.

Referring to the achieved result to the research question two, in perceptual or sensory learning style, females found to be more visual and kinesthetic whereas males were observed to be more auditory.

It can be said that engineering student's classroom is based on multiple learning styles. In perceptual learning style dimension the results of this research showed most dominating learning styles were kinesthetic, which is supported by the Ictenbas and Eryilmaz (2011), stated that the Kinesthetic learning style was the mainly preferred learning style among different types of engineering students. Further studies are also in line with Ramburuth and McCormick (2001), Moenikia, Alipour and Ghaderi, (2009), Bahadori, Sadeghifar, Tofighi, Mamikhani, and Nejati (2011). Ramburuth and Mccormick (2001) stated that Asian learners were more auditory and kinesthetic and they possibly showed group learning pattern which is in our case extrovert learning style. However, the present study results are different with the results of the study that established that most of the students were visual based on the investigation of perceptual learning style preferences of Palestinian students (Naqeeb \& Awad, 2011). There may be various reasons that cause this dissimilarity in the educational system of Pakistan; for instance, instructors do not employ visual assistances in their instructional methods. The learners in this case are habitual of using auditory or any other style instead of using visual in higher studies as well.

According to the results of this study all the learning styles have shown a positive correlation between learning styles and scanning information in text scores. Generally, it is assumed that only VARK can have a relationship with reading achievement. But when investigated in this study it was found that all 23 learning styles have a positive correlation between scanning skills the most important reading skill. Every individual has his own unique learning style with the help of which he or she learns anything. It is difficult for the instructor to accommodate all different individuals in one learning style. There were some studies that have conducted on the correlation or relationship between learning style preferences and reading comprehension or reading achievement, but no study has been found in the correlation between learning style preferences and scanning information in text or simple scanning skill a basic reading strategy or reading skill.

The results of the present study are similar to Jafarpanah, and Farahian (2016) showed that there is a strong positive correlation between learning strategies and Iranian EFL learning styles. The results are also in line with Jafarpanah and Farahian (2016) demonstrated that there was a strong correlation between visual and auditory with metacognitive reading strategy. Another study of Gürses and Bouvet (2016) found to be parallel with this study validated the results that learning style affects the use of reading strategies. Further, Sadeghi, Kasim, Tan and Abdullah (2012) shared the related result in the research that there was a correlation between learning styles and reading comprehension.

The results of the present study exposed that a correlation exists between learning styles of engineering students and scanning information in the text. This deduction has some implications. The purpose of this research was twofold the first was to draw the attention of all the teachers and instructors towards the students' individual unique learning style and secondly, to assert how far learning styles were related and important for teaching and learning reading skills. Moreover, the researcher also highlighted the misinterpretation of reading comprehension and scanning skill that is scanning information in the text. The research has proved that there is a correlation between learning Perceptual learning style preferences and scanning information in text scores of engineering 
students at the undergraduate level at Public Sector University.

\section{References}

Akhlaghi, N., Mirkazemi, H., Jafarzade, M., \& Akhlaghi, N. (2018). Does learning style preferences influence academic performance among dental students in Isfahan, Iran? Journal of Educational Evaluation for Health Professions, 15. https://doi.org/10.3352/jeehp.2018.15.8

Anderson, N. J. (1991). Individual differences in strategy use in second language reading and testing. The Modern Language Journal, 75(4), 460-472. https://doi.org/10.1111/j.1540-4781.1991.tb05384.x

Bahadori, M., Sadeghifar, J., Tofighi, S., Mamikhani, J. A., \& Nejati, M. (2011). Learning styles of the health services management students: a study of first-year students from the medical science universities of Iran. Australian Journal of Basic and Applied Sciences, 5(9), 122-127.

Bransford, J. D., Franks, J. J., Morris, C. D., \& Stein, B. S. (1979). Some general constraints on learning and memory research (pp. 331-354). Levels of processing in human memory.

Brown, J. (2007). An application of learning and teaching styles: A case study of science and engineering seminars. Teaching and Learning Forum [online] [Cited 12 April 2008].

Carbo, M. (1984). Matching Teaching \& Learning Styles. Research in Learning Style and Reading: Implications for Instruction, Theory into Practice, 23(1), 72-76. https://doi.org/10.1080/00405848409543092

Carbo, M., Dunn, R., \& Dunn, K. (1986). Teaching students to read through their individual learning styles. New Jersey: Prentice-Hall, Inc.

Claxton, C. S., \& Ralston, Y. (1978). Learning Styles: Their Impact on Teaching and Administration. AAHE-ERIC/Higher Education Research Report No. 10.

Cohen, A. D., Oxford, R. L., \& Chi, J. C. (2001). Learning style survey. Retrieved May, 19, 2005.

Cohen, A. D., Oxford, R. L., \& Chi, J. C. (2003). Learning style survey: Assessing your own learning styles. Regents of the University of Minnesota, 151-161.

Creswell, J. W. (2002). Educational research: Planning, conducting, and evaluating quantitative (pp. 146-166). Upper Saddle River, NJ: Prentice Hall.

Dreher, M. J. (1992). Searching for information in textbooks. Journal of Reading, 35(5), 364-371.

Dreher, M. J., \& Guthrie, J. T. (1990). Cognitive processes in textbook chapter search tasks. Reading Research Quarterly, 25, 323-339. https://doi.org/10.2307/747694

Dreher, M. J., \& Guthrie, J. T. (1993). Searching for information. Contemporary Educational Psychology, 18(2), 127-279. https://doi.org/10.1006/ceps.1993.1013

Farooq, M. S., \& Regnier, J. C. (2011). Role of learning styles in the quality of learning at different levels. Informatica Economica, 15(3), 28.

Felder, R. M., \& Henriques, E. R. (1995). Learning and teaching styles in foreign and second language education. Foreign Language Annals, 28(1), 21-31._https://doi.org/10.1111/j.1944-9720.1995.tb00767.x

Fleming, N. D. (1987). VARK inventory.

Fleming, N. D. (1995, July). I'm different; not dumb. Modes of presentation (VARK) in the tertiary classroom (Vol. 18, pp. 308-313). In Research and Development in Higher Education, Proceedings of the 1995 Annual Conference of the Higher Education and Research Development Society of Australasia (HERDSA), HERDSA.

Geoghegan, S. M. (1996). Modality and Learning Style among Basic Skills Students.

Grasha, A. F. (1996). Teaching with style: Practical Guide to Enhancing Learning by Understanding Teaching and Learning Styles. Pittsburg, PA: Alliance Publishers.

Griggs, S. A., \& Price, G. E. (1981). Self-concept relates to learning style in the junior high. The Phi Delta Kappan, 62(8), 604.

Gujjar, A. A., \& Tabassum, R. (2011). Assessing learning styles of student teachers at federal college of education. Procedia-Social and Behavioral Sciences, 30, 267-271. https://doi.org/10.1016/j.sbspro.2011.10.053

Gürses, M. Ö., \& Bouvet, E. (2016). Investigating Reading Comprehension and Learning Styles in Relation to 
Reading Strategies in L2. Reading in a Foreign Language, 28(1), 20-42.

Guthrie, J., Siefert, M., \& Kirsch, I. (1986). Effects of Education, Occupation and Setting on Reading Practice. American Educational Research Journal, 23, 151-160. https://doi.org/10.3102/00028312023001151

Guthrie, J. T. (1988). Locating information in documents: Examination of a cognitive model. Reading Research Quarterly, 23(2), 178-199. https://doi.org/10.2307/747801

Hashwani, M. S. (2000). Reading difficulties in children.

Ictenbas, B. D., \& Eryilmaz, H. (2011). Determining learning styles of engineering students to improve the design of a service course. Procedia-Social and Behavioral Sciences, 28, 342-346. https://doi.org/10.1016/j.sbspro.2011.11.065

Jaeger, B. K., Whalen, R., \& Freeman, S. (2007). Do they Like What They Learn, Do They Learn What They LikeAnd What Do We Do About It? In Proceedings of the 2007 American Society of Engineering Education Annual Conference \& Exposition.

Jafarpanah, Z., \& Farahian, M. (2016). The relationship between learning styles and metacognitive reading strategy of EFL learners. International Research in Education, 4(1), 47-54. https://doi.org/10.5296/ire.v4i1.8383

Jordan, B. T. (1980). Left-Right Reversal Test. Novato.

Khurshid, F., \& Mahmood, N. (2012). Learning styles of natural sciences, social sciences and humanities students at graduate level. Interdisciplinary Journal of Contemporary Research in Business, 3(9), 672-678.

Kirsch, I., \& Jungeblut, A. (1986). Literacy: Profiles of America's young adults. Princeton, NJ: Educational Testing Service.

Kirsch, I. S., \& Mosenthal, P. B. (1990). Exploring document literacy: Variables underlying the performance of young adults. Reading Research Quarterly, 25(1),5-30. https://doi.org/10.2307/747985

Mikulecky, L. (1982). Job literacy: The relationship between school preparation and workplace actuality. Reading Research Quarterly, 17(3), 400-419. https://doi.org/10.2307/747527

Moenikia, M., Alipour, A., \& Ghaderi, E. (2009). Study of learning styles and their roles in the academic achievement of the students of Payame Noor University. Turkish Online Journal of Distance Education, 10, $17-28$.

Naqeeb, H., \& Awad, A. (2011). Learning styles as perceived by learners of English as a foreign language in the English language center of the Arab American University-Jenin, Palestine. An-Najah University Journal for Research, 25(8), 2231-2256.

Oxford, R. L. (Ed.). (2003). Language learning styles and strategies. Mouton de Gruyter. https://doi.org/10.1515/iral.2003.012

Price, G. E., Dunn, R., \& Sanders, W. (1981). Reading achievement and learning style characteristics. The Clearing House: A Journal of Educational Strategies, Issues and Ideas, 54(5), 223-226. https://doi.org/10.1080/00098655.1981.9957163

Rahim, P. R. M. A. (2018). Facilitating Reading Comprehension among ESL Learners. Malaysian Journal of ELT Research, 13(1), 30-42.

Ramburuth, P., \& McCormick, J. (2001). Learning diversity in higher education: A comparative study of Asian international and Australian students. Higher Education, 42(3), 333-350. https://doi.org/10.1023/A:1017982716482

Reid, J. (1987). The learning style preferences of ESL students. TESOL Quarterly, 21, 87-111. https://doi.org/10.2307/3586356

Sadeghi, N., Kasim, Z. M., Tan, B. H., \& Abdullah, F. S. (2012). Learning styles, personality types and reading comprehension performance. English Language Teaching, 5(4), 116-123. https://doi.org/10.5539/elt.v5n4p116

Sarabi-Asiabar, A., Jafari, M., Sadeghifar, J., Tofighi, S., Zaboli, R., Peyman, H., ... \& Shams, L. (2015). The relationship between learning style preferences and gender, educational major and status in first year medical students: a survey study from Iran. Iranian Red Crescent Medical Journal, 17(1). https://doi.org/10.5812/ircmj.18250 
Sarasin, L. C. (1999). Learning style perspectives: Impact in the classroom. Atwood Pub.

Scanlon, D., \& Deshler, D. D. (8). Schumaker, JB (1996). Can a strategy be taught and learned in secondary inclusive class-rooms. Learning Disabilities Research and Practice, 1(1), 41-57.

Shaheen, M. (2015). Exploring the relationship between the beliefs and practices of an English teacher in reading instruction in a private school in karachi. Pakistan.

Shea, T. C. (1983). An investigation of the relationship among preferences for the learning style element of design, selected instructional environments and reading achievement of ninth grade students to improve administrative determinations concerning effective educational facilities. Unpublished doctoral dissertation, St. John's University.

Smith, L., \& Renzulli, J. (1984). Learning style preference: A practical approach for classroom teachers. Theory into Practice, 23(1), 45-50.

Spretnak, C. M. (1983). Reading and writing for engineering students. Journal of Advanced Composition, 133137.

Williams, J. (2010). Reading comprehension, learning styles, and seventh grade students. Unpublished Doctoral Dissertation, Lynchburg: Liberty University.

Yussen, S., \& Stright, A. (1991). Simple searching to find information in a textbook. Paper presented at the American Educational Re-search Association meeting, Chicago, IL.

\section{Copyrights}

Copyright for this article is retained by the author, with first publication rights granted to the journal.

This is an open-access article distributed under the terms and conditions of the Creative Commons Attribution license (http://creativecommons.org/licenses/by/4.0/). 